\section{BMJ Open} Ophthalmology

\title{
National application of the European visual field standards for driving: a survey study
}

\author{
Thea Melsen Sudmann (D) , ${ }^{1}$ Thora Elisabet Jonsdottir, ${ }^{2}$ Fiona J Rowe (D) , ${ }^{3}$ \\ Øystein Kalsnes Jørstad (iD) 2,4
}

To cite: Sudmann TM, Jonsdottir TE, Rowe FJ, et al. National application of the European visual field standards for driving: a survey study. BMJ Open Ophthalmology 2022;7:e000904. doi:10.1136/ bmjophth-2021-000904

- Additional supplemental material is published online only. To view, please visit the journal online (http://dx.doi. org/10.1136/bmjophth-2021000904).

Received 16 September 2021 Accepted 28 January 2022

Check for updates

\section{(c) Author(s) (or their} employer(s)) 2022. Re-use permitted under CC BY-NC. No commercial re-use. See rights and permissions. Published by BMJ.

${ }^{1}$ Department of Ophthalmology, Hospital of Southern Norway, Arendal, Norway

${ }^{2}$ Department of Ophthalmology, Oslo University Hospital, Oslo, Norway

${ }^{3}$ Faculty of Health and Life Sciences, University of Liverpool, Liverpool, UK

${ }^{4}$ Faculty of Medicine, University of Oslo, Oslo, Norway

Correspondence to Dr Thea Melsen Sudmann; theamelsen@gmail.com

\section{ABSTRACT}

Aims To provide an overview of how the European visual field standards for driving (specified in Commission Directive 2009/113/EC) are applied and determine whether individuals with visual field defects are treated equally across Europe.

Methods One ophthalmic expert from each of 32 European countries was invited to participate in an electronic survey. They were presented with threshold and Esterman perimetry results of 15 cases of visual field defects and asked to classify each case as either passed or failed in reference to their national standards. The results were compared with the European Driving Test Group 1 (EDT1), which is a new perimetry algorithm that adheres to the recommendations by the Eyesight Working Group. Fleiss' kappa was used to determine the inter-rater agreement.

Results Twenty-five countries responded. Three of 15 cases were passed by all. Full agreement on a failed case was not reached. Denmark graded most leniently and passed 12 cases. Bulgaria, Romania and Slovakia graded most strictly and passed five cases. The Fleiss' kappa score was 0.52 (95\% Cl 0.49 to 0.55). Only Slovenia was in full agreement with the EDT1. Fifteen countries endorsed specific perimetric tests for assessing fitness to drive. Five of these also defined pass/fail criteria.

Conclusion The directive fails to establish a uniform approach to the visual field requirements, as evident by moderate pass/fail agreement between the national experts. Because the visual standards for driving are enforced differently, identical visual field loss can result in either revocation or approval of a driving license.

\section{INTRODUCTION}

The European Union (EU) has adopted the Swedish Vision Zero initiative and aims at reducing road deaths to almost zero by $2050 .{ }^{12}$ A key legislation in this regard is the Commission Directive 2009/113/EC, which defines medical standards for European drivers. ${ }^{3}$ Notably, each EU member state is required to incorporate these standards into its national law. Driving safely warrants adequate eyesight, and accordingly the directive places particular emphasis on the visual acuity and visual field. For holders of group 1 driving licenses (car and motorcycle), the binocular

\section{Key messages}

What is already known about this subject?

- The Commission Directive 2009/113/EC defines the visual standards for driving in Europe.

The directive places emphasis on the visual field but omits to establish which perimetry algorithm should be used and how its results should be interpreted.

\section{What are the new findings?}

- There is only a moderate level of agreement for determination of pass/fail of visual fields between national experts.

- The directive is enforced differently between European member states through the use of a variety of perimetry programmes.

In consequence, identical visual field loss can result in either revocation or approval of a driving licence.

How might these results change the focus of research or clinical practice?

- A uniform traffic perimetry algorithm should be used to make certain that the visual field is consistently evaluated.

best-corrected visual acuity (BCVA) must be at least 0.5 and the binocular visual field at least $120^{\circ}$ horizontally (minimum of $50^{\circ} \mathrm{left}$ and right) and $40^{\circ}$ vertically (minimum of $20^{\circ}$ up and down); no defects should be present within a radius of the central $20^{\circ}$.

If there is doubt about whether the visual requirements are met, the driver must be examined by a specialist. While it is relatively straightforward to determine the BCVA, an accurate assessment of the visual field implies the use of perimetry. In this regard, an important topic is left out of the directive: which perimetry algorithm should be used and how should its results be interpreted in terms of a passed or failed test? Omitting this brings risk for varying visual field standards. For instance, there are differing practices in the five Nordic countries, and although the UK and Norway both use the Esterman programme to determine driving eligibility in the case of visual field loss, the results are 
interpreted more leniently in the UK. ${ }^{45}$ Consequently, similar visual fields may be judged differently. Despite the best of intentions to improve road safety, the EU legislation thereby challenges the right of European drivers for legal equality.

The purpose of this study was to provide an overview of how the European visual field standards for driving are applied and determine whether individuals with visual field defects are treated equally across the member states of EU and European Free Trade Association (EFTA) and the UK.

\section{MATERIALS AND METHODS}

This was a survey study. The participants were ophthalmic healthcare professionals with special competence in visual standards for driving. One expert from each of the 27 EU member states, the 4 EFTA member states (Iceland, Liechtenstein, Norway and Switzerland) and the UK was invited to participate. Except for the UK and Norway, the experts were selected by asking each national ophthalmology society to recommend a specialist with high competence in visual standards for driving. In the UK and Norway (our own countries), we invited an expert who was independent of our study group. The survey data were collected from January to April 2021.

The experts responded to an electronic questionnaire, which anonymously presented monocular $30^{\circ}$ threshold perimetry (the Octopus $\mathrm{G}$ programme) and binocular Esterman perimetry results of 15 cases of visual field defects affecting both eyes. The cases were selected by purposive sampling of patients who were referred to the Department of Ophthalmology at Oslo University Hospital for assessment of fitness to drive and included examples in the range from mild to severe visual field loss. The patients were also examined with a new binocular suprathreshold test, the European Driving Test Group 1 (EDT1), which adheres to the European visual field requirements for group 1 driving licenses. ${ }^{5}$ The experts were blinded to the EDT1 results. To ensure reliable perimetry examinations, trained ophthalmic nurses supervised the tests and no more than three false answers were allowed. Threshold perimetry was performed first. Esterman and EDT1 perimetry were then performed in random order.

The experts were asked to classify each case as either passed or failed in reference to their national visual standards for driving and on the premises that the perimetry results were reproducible, and that the visual acuity requirement (binocular BCVA of at least 0.5) was met. None of the experts participated in an actual assessment of fitness to drive, that is, their setting was hypothetical. The experts were also asked about whether their national guidelines endorsed a particular perimetry algorithm for assessing fitness to drive in the setting of visual field loss and whether pass/fail criteria were specified. The information provided in the electronic questionnaire is available as online supplemental information.
Fleiss' kappa analysis was used to determine the interrater agreement between the experts. The results are otherwise presented with descriptive statistics.

\section{RESULTS}

Twenty-five of 32 European countries responded to the survey. There was full pass/fail agreement in 3 of the 15 cases of visual field loss; cases 11, 12 and 13 were passed by all experts. Full agreement on a failed case was not reached. Figure 1 shows one of the cases (number 15) that caused strong disagreement, with a pass/fail proportion of nearly 50:50. Denmark graded most leniently and passed 12 of the 15 cases. Bulgaria, Romania and Slovakia graded most strictly and passed 5 of the 15 cases. The Fleiss' kappa score was 0.52 (95\% CI 0.49 to 0.55 ), indicating a 'moderate' level of agreement between the national experts. ${ }^{6}$ Figure 2 shows the relationship between Esterman score and passed proportion for the 15 cases.

Fourteen of the 15 cases were also examined with the EDT1. Slovenia reached the same pass/fail conclusion as the EDT1 in all the 14 cases and was hence in full agreement with the EDT1. Conversely, Greece reached the same pass/fail conclusion as the EDT1 in 7 of the 14 cases. Table 1 displays the pass/fail conclusion and level of agreement with the EDT1 for each case per country. It should be noted that experts with the same proportion of passed cases may disagree about which cases to pass. For instance, both the Greek and Slovenian expert passed 9 of 15 cases, but only the Slovenian was in full agreement with the EDT1. Because case 14 was lost to follow-up, an EDT1 result was not available for this case.

Fifteen of 25 countries endorsed specific perimetric tests for assessing fitness to drive in the setting of visual field loss. Three countries used the Esterman programme, two countries used threshold perimetry and nine countries used a combination of threshold perimetry and the Esterman programme. Five of these 15 countries also defined pass/fail criteria for the endorsed tests. Austria endorsed a special perimetric test, the Führerscheingutachten (FG) programme, which was not presented in this study. In 10 of 25 countries, national guidelines did not recommend a particular test. Table 2 gives an overview of the endorsed perimetric tests for assessing fitness to drive among the 25 countries.

Table 3 shows the pass/fail criteria in the five countries that defined such. It should be noted that the Danish guidelines were issued by the Danish ophthalmology society, not the state authorities.

\section{DISCUSSION}

The Commission Directive 2009/113/EC defines the European visual standards for driving, which all EU member states must incorporate into their national laws. Yet, the directive fails to establish a uniform approach to the visual field requirements. This survey study shows that there is only a moderate level of agreement for determination of pass/fail between national experts. As shown 

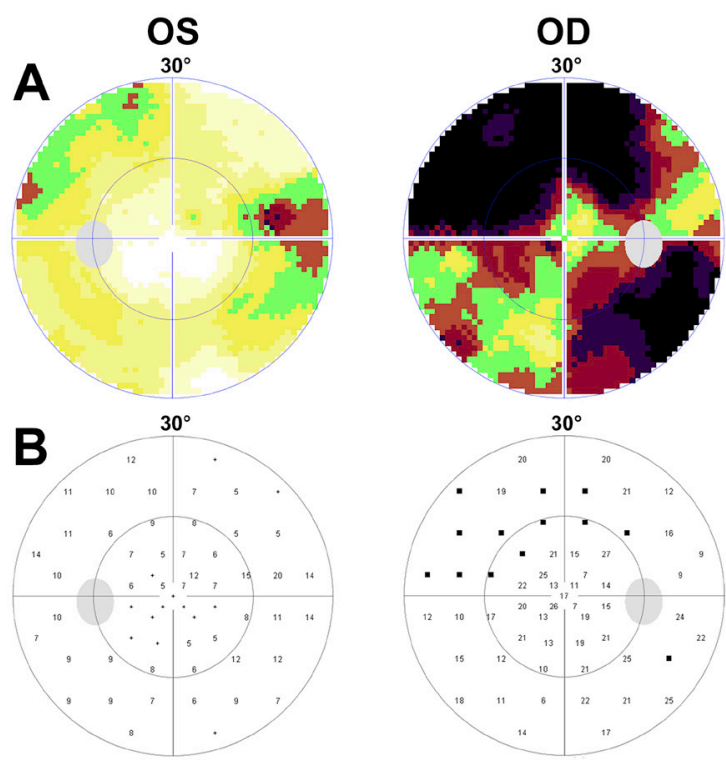

C

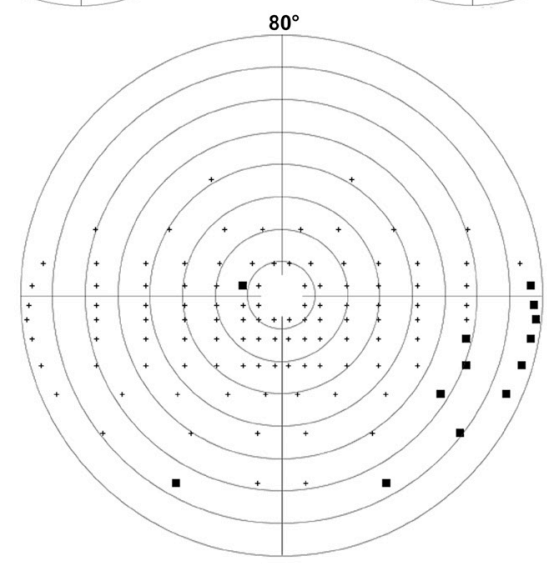

D

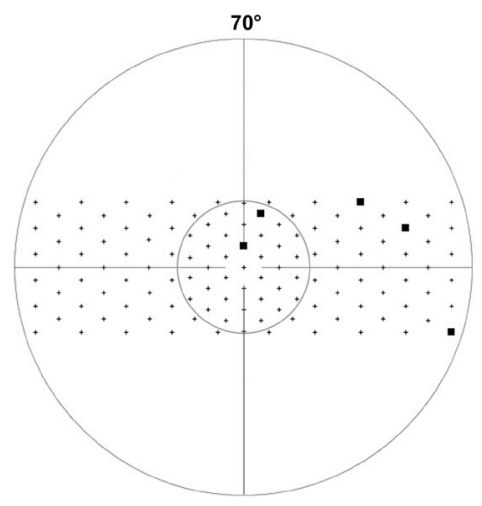

Figure 1 Monocular $30^{\circ}$ threshold perimetry (A, B), binocular Esterman (C)perimetry and European Driving Test Group 1 (EDT1) perimetry (D) of case 15 (a patient with bilateral glaucoma more advanced in the right eye). The case was passed by 16 experts and failed by 9 experts. At least three adjacent missed test points within $20^{\circ}$ or at least nine missed test points within $120^{\circ} \times 40^{\circ}$ defined a failed EDT1 result in the study, and the patient thus passed the EDT1 test. Notice that the test points are differently placed for EDT1 and Esterman; EDT1 has more central test points and the same number of test points in the upper and lower hemisphere, whereas Esterman extends to $80^{\circ}$ horizontally. Accordingly, the EDT1 and Esterman findings are not identical. OS, left eye; OD, right eye.

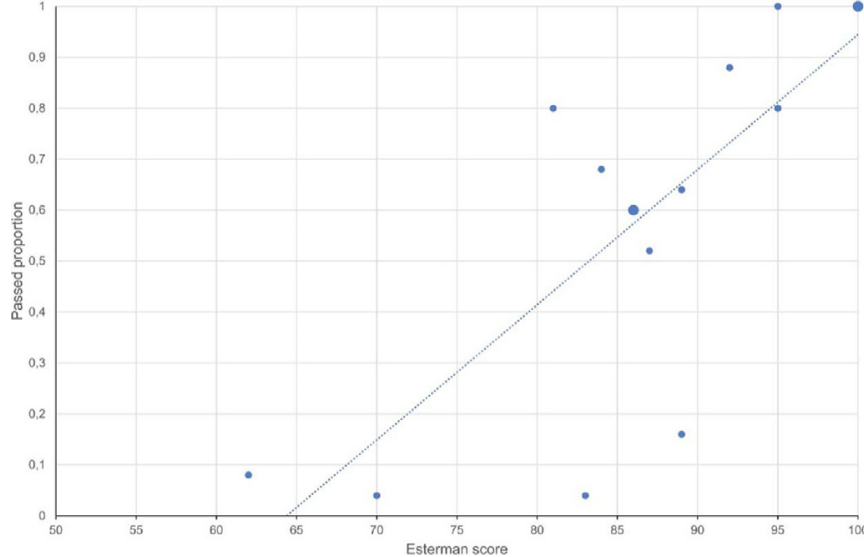

Figure 2 Scatter plot with line of best fit displaying the relationship between Esterman score and passed proportion for the 15 cases in the study (larger dots represent two cases). A passed proportion of 0 or 1 indicates full agreement between the 25 European experts (case failed or passed by all experts, respectively).

in figure 2, there was generally high agreement for the cases with best and worst visual fields, which were passed and failed by most experts respectively. However, for Esterman scores between 80 and 90, there was disagreement for several cases, reflecting that borderline visual fields in particular cause controversy about fitness to drive. The study also shows that the directive is enforced differently between European member states through the use of a variety of perimetry programmes and that few countries define pass/fail criteria. Consequently, identical visual field loss can result in either revocation or approval of a driving license. This is a breach of Article 20 of the Charter of Fundamental Rights of the EU, which states that everyone is equal before the law. ${ }^{7}$

Unrestricted movement of people across the internal borders of the Schengen Area is a fundamental principle in Europe. European citizens frequently cross these borders by car, which requires each member state to recognise driving licenses issued by the others. In this regard, the disagreement in this study poses a dilemma: a driver with visual field loss may meet the visual standard of his or her home country but not those of another. For instance, case 2 in the study fulfilled the visual field requirements in Denmark but not in Norway, and a Danish driver with this visual field would in principle be legally prohibited from driving in Norway. This raises concern about foreign jurisdiction, undermining the very idea of free movement within Europe from the perspective of its drivers.

In practice, the issue of visual field standards for driving is inseparable from the choice of perimetric test. Judgement of a visual field will indisputably depend on how it was measured. Also, for a given test specific pass/ fail criteria are necessary to avoid ambiguity, such as in the case of the Esterman programme used in Ireland, the UK and Norway, as shown in table 3. While omitted from the Commission Directive 2009/113/EC, the underlying 


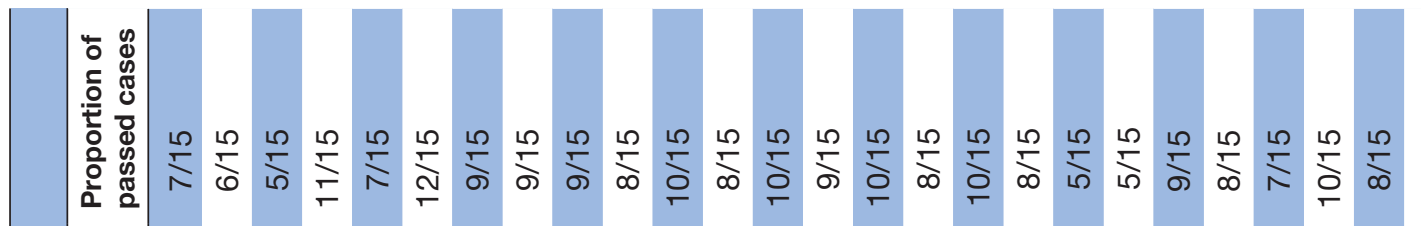

苍云

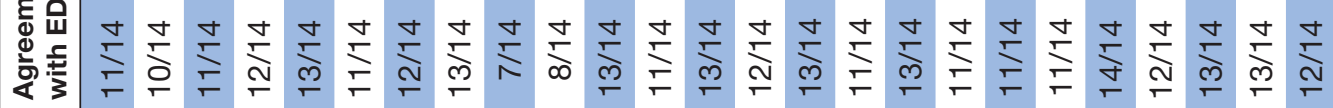

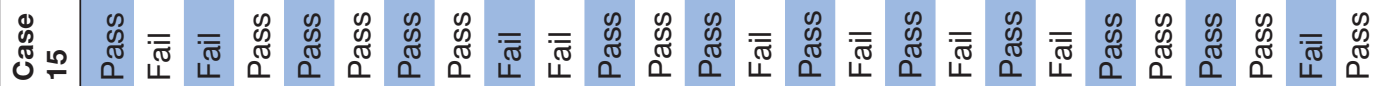

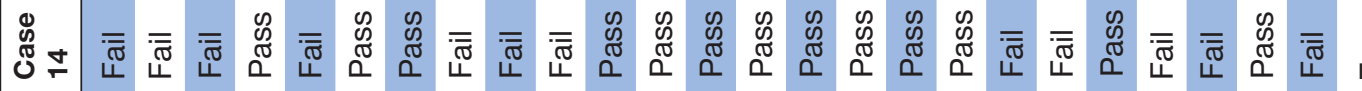

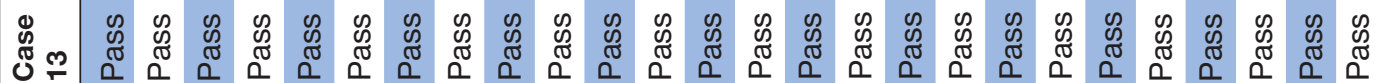

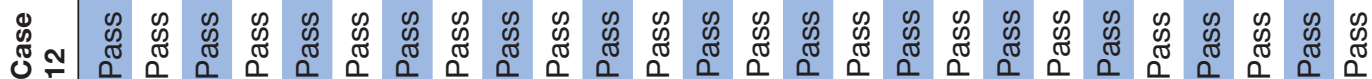

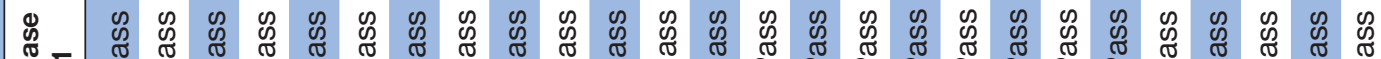

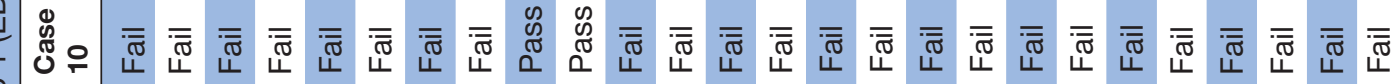

峁 $\overline{\bar{\sigma}} \overline{\bar{\sigma}} \overline{\bar{\sigma}} \overline{\bar{\sigma}} \overline{\bar{\sigma}} \frac{\infty}{\infty} \overline{\bar{\sigma}} \overline{\bar{\sigma}} \overline{\bar{\sigma}} \overline{\bar{\sigma}} \overline{\bar{\sigma}} \overline{\bar{\sigma}} \overline{\bar{\sigma}} \overline{\bar{\sigma}} \overline{\bar{\sigma}} \overline{\bar{\sigma}} \overline{\bar{\sigma}} \overline{\bar{\sigma}} \overline{\bar{\sigma}} \overline{\bar{\sigma}} \overline{\bar{\sigma}} \overline{\bar{\sigma}} \overline{\bar{\sigma}} \overline{\bar{\sigma}} \overline{\bar{\sigma}} \overline{\bar{\sigma}}$

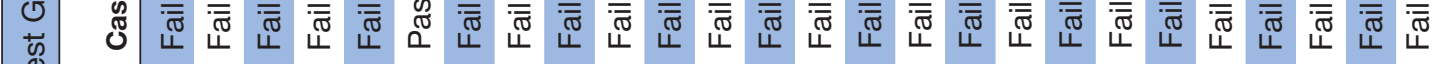

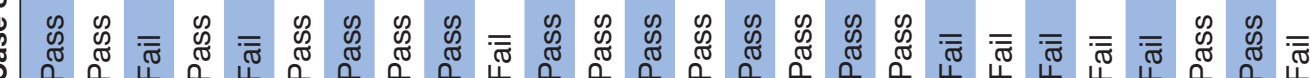

$\hat{~}=g^{2}=1$

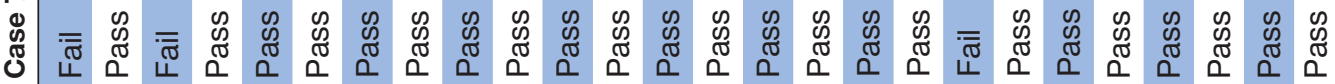

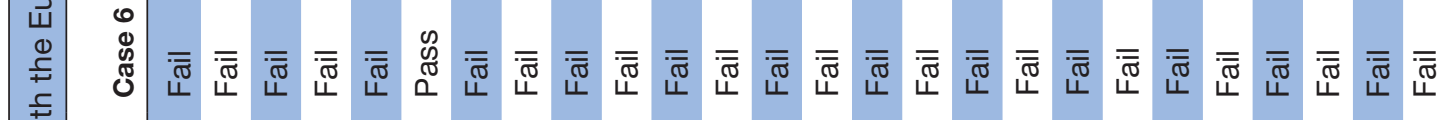

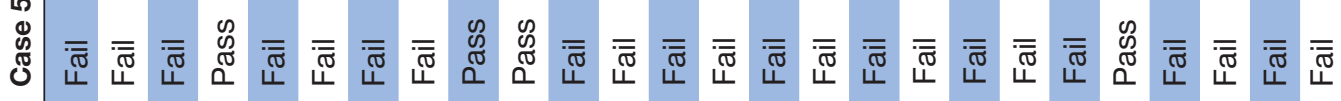

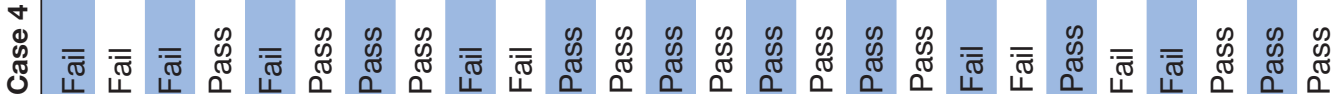

m

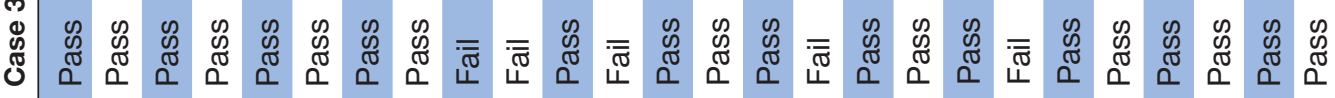

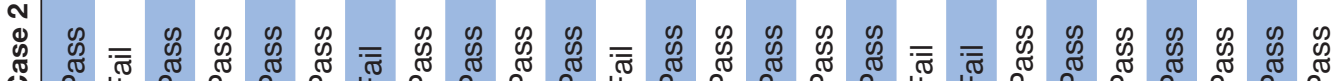

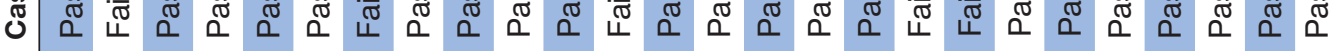

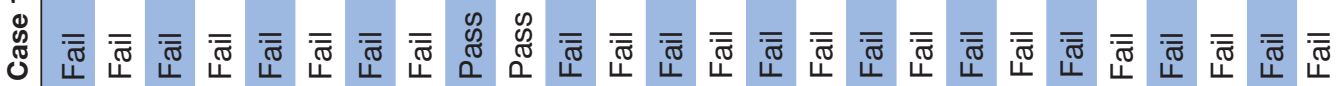


Table 2 Endorsed perimetric tests for assessing fitness to drive in the setting of visual field defects, according to national guidelines

UK, Ireland and Norway

Estonia and Romania

Belgium, Cyprus, Denmark, Greece, Iceland, Italy, Latvia, Lithuania and Sweden

Austria

Bulgaria, Czechia, Finland, Hungary, Malta, The Netherlands, Slovakia, Slovenia, Spain and Switzerland

\section{Esterman}

Threshold perimetry

A combination of threshold perimetry and Esterman

A special two-level suprathreshold test

(Führerscheingutachten programme)

Kinetic perimetry (Goldmann) might be used in doubtful cases

National guidelines do not endorse a particular perimetric test

report by the Eyesight Working Group underscores the need for a uniform traffic perimetry algorithm to make certain that the visual field is consistently evaluated. ${ }^{8}$ The report even describes specifications and pass/fail criteria of such an algorithm, which overall, should be a static, suprathreshold programme that examines the binocular visual field. The EDT1 adheres to these specifications and will be available in the upcoming software upgrade for the Octopus 900 perimeter from Haag-Streit. EDT1 provides a tool for validating the current legislation and will hopefully be a step towards guidelines and recommendations supported by better evidence. Availability of widefield perimeters is also an issue to be resolved before actual visual field standards become a reality in Europe.

\section{LIMITATIONS}

This study is subject to several limitations. First, it should be noted that we only invited one expert per European country to participate in the study. For a country with precise visual field standards, the expert's responses expectedly represent the general perimetry practice. This is the case for Norway, for instance, in which national guidelines leave little doubt about when to pass or fail a visual field. However, the survey revealed that $40 \%$ of the responding countries lacked national guidelines on assessment of the visual field. Although all experts were specifically tasked with responding for typical perimetry practice for their country, it is possible that responses from experts lacking national guidelines first and foremost represented personal practice. While

\section{Table 3 Pass/Fail criteria, according to national guidelines}

$\mathrm{UK}^{9}$ and The following are generally regarded as acceptable central loss (on Esterman):

Ireland $^{10} \longrightarrow$ Scattered single missed points

- A single cluster of up to three adjoining points

The following are generally regarded as unacceptable central loss (on Esterman):

- A cluster of four or more adjoining points that is either wholly or partly within the central $20^{\circ}$ area.

- Loss consisting of both a single cluster of three adjoining missed points up to and including $20^{\circ}$ from fixation, and any additional separate missed points within the central $20^{\circ}$ area.

- Any central loss that is an extension of hemianopia or quadrantanopia of size greater than three missed points.

The following will be disregarded when assessing the width of field (on Esterman):

- A cluster of up to three adjoining missed points, unattached to any other area of defect, lying on or across the horizontal meridian.

- A vertical defect of only single-point width but of any length, unattached to any other area of defect, which touches or cuts through the horizontal meridian.

\begin{tabular}{|c|c|}
\hline Norway $^{11}$ & $\begin{array}{l}\text { The following is generally regarded as unacceptable central loss (on Esterman): } \\
\text { Any missed test point within } 20^{\circ} \text {. } \\
\text { The following is generally regarded as unacceptable peripheral loss (on Esterman): } \\
\text { A cluster of four or more missed test points. }\end{array}$ \\
\hline Denmark $^{12}$ & $\begin{array}{l}\text { The following are generally regarded as unacceptable central loss (on threshold perimetry): } \\
\text { At least two } 0 \mathrm{~dB} \text { test points in the integrated visual field within } 20^{\circ} \text {. } \\
\text { A mean defect of }>15 \mathrm{~dB} \text { for the best eye. } \\
\text { The following are generally regarded as unacceptable peripheral loss (on Esterman): } \\
\text { More than three missed adjacent test points. } \\
\text { More than five missed test points in total. }\end{array}$ \\
\hline Sweden $^{13}$ & $\begin{array}{l}\text { The following are generally regarded as unacceptable central loss (on threshold perimetry): } \\
\text { Any test point of }<20 \mathrm{~dB} \text { in the integrated visual field within } 10^{\circ} \text {. } \\
\text { Two or more test points of }<10 \mathrm{~dB} \text { in the integrated visual field within } 20^{\circ} \text {. } \\
\text { The following is generally regarded as unacceptable peripheral loss (on Esterman): } \\
\text { More than two missed adjacent test points. }\end{array}$ \\
\hline
\end{tabular}


we conclude that the $\mathrm{EU}$ directive fails to establish a uniform approach to the visual field requirements, we want to point out that the failure probably asserts itself at two levels: nationally and internationally. The degree of inter-rater disagreement at a national level, in particular where national guidelines lack, is a topic for future study. Second, it should be noted that because Austria endorsed a special perimetric test, the FG programme, which was not included in this study, the pass/fail conclusion of its national expert may be inaccurate. Finally, we acknowledge that the experts were tasked with judging a combination of perimetry algorithms that did not accurately adhere to the visual field standards for driving. In the review process, for instance, our choice of threshold test was questioned, and we agree that the Octopus $G$ programme is not ideal for determining whether the central visual field standards are met. Instead, it would be better if we had a threshold perimetry programme that specifically examined the central $20^{\circ}$ with a sufficient number of test points. One can raise the same concern about using the Esterman programme to determine whether the peripheral visual field standards were met. At the end of the day, this underscores that the issue of visual field standards is inseparable from the choice of perimetric test, and unless the test and standards adhere, disagreement is inevitable. Other combinations of perimetry algorithms may have brought different results in our study.

In conclusion, this European survey study of visual field driving assessment shows disagreement in determination of pass/fail across a range of mild to severe visual field loss, as well as wide variance in perimetry programmes chosen. Further work is required to reach consensus on perimetry programme choice and pass/fail criteria.

Acknowledgements We wish to thank the following national experts for participating in the survey (in alphabetical order): Bertram Vidic, MD (Austria), Tanja Coeckelbergh, PhD (Belgium), Andreas Kontos, MD (Cyprus), Pavel Diblík, MD (Czechia), Peter Bruvik Ruhlmann, MD (Denmark), Maris Rebane, MD (Estonia), Jaana Penna, MD (Finland), Tryfonas Rotsos, MD, PhD (Greece), Gabor Nemeth, MD, PhD (Hungary), Helgi Daví̃ Björnsson, MD (Iceland), Fiona Kearns, MD (Ireland), Renato De Natale, MD (Italy), Katrine Morkane, MD (Latvia), Ausra Povilauskiene, MD (Lithuania), David Cauchi, MD (Malta), Nomdo M. Jansonius, MD, PhD (The Netherlands), Einar Krefting, MD (Norway), Daniela Manasia, MD, PhD (Romania), Denisa Jurenová, MD (Slovakia), Marko Hawlina, MD, PhD (Slovenia), Antonio Ferreras, MD, PhD, MBA (Spain), Frank Träisk, MD, PhD (Sweden), Frank Blaser, MD, DI (Switzerland), Claire Howard, PhD (UK) and the expert from Bulgaria, who preferred to be anonymous in this paper.

Contributors All authors planned the study. TEJ and ØKJ examined the patients. TMS collected the survey data. TMS and ØKJ drafted the manuscript. All authors provided critical feedback and contributed to the final manuscript.

Funding This research received no specific grant from any funding agency in the public, commercial, or not-for-profit sectors.
Competing interests FJR has research perimeters from Haag-Streit AG and Zeiss Meditec and is a consultant to Haag Streit AG. The EDT1 test is a non-commercial, clinician researchers initiative and has public domain status.

Patient consent for publication Consent obtained directly from the patients.

Ethics approval Approval for the study was granted by the Institutional data protection officer at Oslo University Hospital (reference 19/15982). All participants provided written informed consent to participate in the study.

Provenance and peer review Not commissioned; externally peer reviewed.

Data availability statement All data relevant to the study are included in the article or uploaded as supplemental information.

Supplemental material This content has been supplied by the author(s). It has not been vetted by BMJ Publishing Group Limited (BMJ) and may not have been peer-reviewed. Any opinions or recommendations discussed are solely those of the author(s) and are not endorsed by BMJ. BMJ disclaims all liability and responsibility arising from any reliance placed on the content. Where the content includes any translated material, BMJ does not warrant the accuracy and reliability of the translations (including but not limited to local regulations, clinical guidelines, terminology, drug names and drug dosages), and is not responsible for any error and/or omissions arising from translation and adaptation or otherwise.

Open access This is an open access article distributed in accordance with the Creative Commons Attribution Non Commercial (CC BY-NC 4.0) license, which permits others to distribute, remix, adapt, build upon this work non-commercially, and license their derivative works on different terms, provided the original work is properly cited, appropriate credit is given, any changes made indicated, and the use is non-commercial. See: http://creativecommons.org/licenses/by-nc/4.0/.

\section{ORCID iDs}

Thea Melsen Sudmann http://orcid.org/0000-0002-2133-4291

Fiona J Rowe http://orcid.org/0000-0001-9210-9131

Øystein Kalsnes Jørstad http://orcid.org/0000-0003-1259-0653

\section{REFERENCES}

1 Kristianssen A-C, Andersson R, Belin Matts-Åke, et al. Swedish vision zero policies for safety - a comparative policy content analysis. Saf Sci 2018;103:260-9.

2 Official website of the EU. Available: https://ec.europa.eu/transport/ road_safety [Accessed 22 Apr 2021].

3 Official Journal of the European Union. Commission directive 2009/113/EC of 25th August 2009 2009;:L223:31-5.

4 Bro T, Lindblom B. Strain out a gnat and swallow a camel? vision and driving in the Nordic countries. Acta Ophthalmol 2018;96:623-30.

5 Jørstad ØK, Jonsdottir TE, Zysset S, et al. A traffic perimetry test that adheres to the European visual field requirements. Acta Ophthalmol 2021;99:e555-61.

6 Landis JR, Koch GG. The measurement of observer agreement for categorical data. Biometrics 1977;33:159-74.

7 Official Journal of the European Union. Charter of fundamental rights of the European Union 2012:C 326/02.

8 Eyesight Working Group. New standards for the visual functions of drivers, 2005. Available: https://ec.europa.eu/transport/road_safety/ sites/roadsafety/files/pdf/behavior/new_standards_final_version_en. pdf [Accessed 07 Jul 2018].

9 GOV.UK. Available: https://www.gov.uk/guidance/visual-disordersassessing-fitness-to-drive [Accessed 03 Aug 2021].

10 Irish Road Safety Authority. Available: https://www.rsa.ie/services/ licensed-drivers/medical-fitness [Accessed 09 Dec 2021].

11 Helsedirektoratet. Available: https://www.helsedirektoratet.no/ veiledere/forerkortveileder [Accessed 03 Aug 2021].

12 Dansk oftalmologisk selskap. Available: https://dansk-oftalmologiskselskab.dk/nuvaerende-guidelines [Accessed 09 Dec 2021].

13 Transportstyrelsen. Available: https://transportstyrelsen.se/TSFS/ TSFS\%202010_125k.pdf [Accessed 09 Dec 2021]. 